Verheij, Henk; Sas, Marc; Hermans, Marcel; Schmidt, Eckard Guidance on the Design of Berthing Structures Related to the Flow Velocities in Ship Thrusters

Verfügbar unter / Available at:

https://hdl.handle.net/20.500.11970/100225

Vorgeschlagene Zitierweise / Suggested citation:

Verheij, Henk; Sas, Marc; Hermans, Marcel; Schmidt, Eckard (2010): Guidance on the Design of Berthing Structures Related to the Flow Velocities in Ship Thrusters. In: Burns, Susan E.; Bhatia, Shobha K.; Avila, Catherine M. C.; Hunt, Beatrice E. (Hg.): Proceedings 5th International Conference on Scour and Erosion (ICSE-5), November 7-10, 2010, San Francisco, USA. Reston, Va.: American Society of Civil Engineers. S. 914-923. 


\title{
Guidance on the Design of Berthing Structures Related to the Flow Velocities in Ship Thrusters
}

\author{
Henk Verheij ${ }^{1}$, Marc Sas ${ }^{2}$, Marcel Hermans ${ }^{3}$, and Eckard Schmidt ${ }^{4}$ \\ ${ }^{1}$ Delft University of Technology and Deltares, P.O. Box 177, 2600 MH Delft, \\ The Netherlands; email: henk.verheij@icteltares.nl \\ ${ }^{2}$ International Marine and Dredging Consultants, Coveliersstraat 15, B-2600 \\ Antwerp, Belgium \\ ${ }^{3}$ Port of Portland, 7200 NE Airport Way, Portland, OR 97218, USA \\ ${ }^{4}$ Knabe Consulting Engineers GmbH, Gasstrasse 18 Haus 4, 22761 Hamburg, \\ Germany
}

\begin{abstract}
Ships have been getting larger and deeper, and simultaneously the installed power of main propellers and bow thrusters has increased. These changes improve the manoeuvrability, but also result in considerably higher flow velocities in the induced jets. Because the bottom of harbour basins are often not designed for these extreme velocities this can lead to bottom erosion and possibly failure of berthing structures. This paper will discuss the procedure for designing complex new berthing facilities as presented in the new PIANC report on this subject.
\end{abstract}

\section{Introduction}

Marine transport is constantly increasing in scale in order to comply with the ever-changing demands of the international market. Ships are becoming larger and deeper, and to facilitate proper manoeuvring most are equipped with main propellers and bow thrusters. As a result of the increase in size and engine power of the propulsion systems the flow velocities have increased considerably. Because the bottom of harbour basins are often not designed for these extreme velocities this can lead to bottom erosion and possible failure of berthing structures (Figure 1). Because of awareness of damage to existing harbour infrastructure and to provide guidance for properly designing future harbour facilities PIANC (Permanent International Association of Navigation Congresses - www.pianc-aipcn.org) installed a committee to prepare new guidelines for the design of berthing structures related to thrusters. The new guidelines (PIANC, 2010) give an overview of modern berthing structures, thrusters, berthing and departures procedures, the design philosophy, procedures to estimate the flow velocities in the thruster jets, and methods to determine size and extent of bottom protection or to estimate the depth of scour holes. The report replaces an older PIANC report (1997); see also Sas et al (2010). This paper will discuss various aspects related to the design of complex new berthing facilities. 


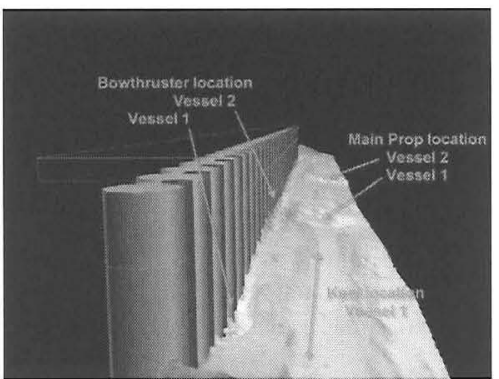

Figure 1. Observed erosion in front of a quay wall

\section{Quay structures}

There are many different berth structures in use throughout the world with water depth at the quay up to $20 \mathrm{~m}$. Berth structures can be characterized in two main groups according to their relevance for the impact of thrusters and main propellers as follows (Figure 2):

A) Solid Berth Structures:

- Sheet pile structures, and

- Gravity structures

B) Open Berth Structures

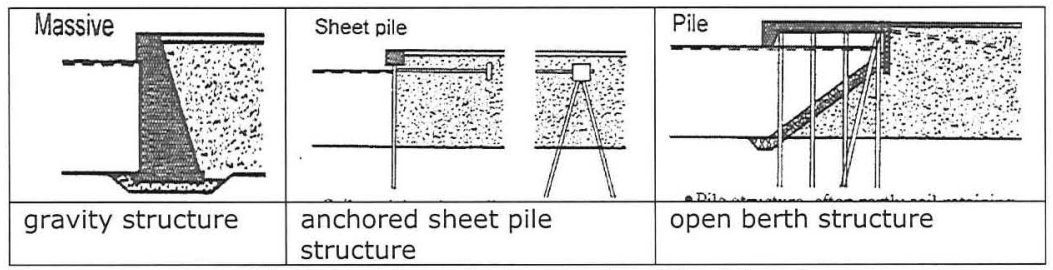

Figure 2. Schematised examples of berthing structures

The scour problem related to Solid Berth Structures is limited to erosion of the bed material in front of the structure, whereas scour related to Open Berth Structures is more complex and can include:

- $\quad$ scour around the piles in particular those near the berthing face, and - scour of the slope underneath the quay, even up to the top.

Although scour can occur near berth structures due to natural currents as well, berth structures are specifically vulnerable to scour caused by vessel's main propeller action and thrusters. Especially during berthing and unberthing, eroding forces on the seabed in front of the berth or on the slope underneath the berth can be substantial. Resulting current velocities due to the action of the main propellers or thrusters can reach up to $8 \mathrm{~m} / \mathrm{s}$ near the bed, while for example the tidal current is typically limited to around 1 or $2 \mathrm{~m} / \mathrm{s}$. 


\section{Propulsion systems}

Container vessels, Ro/Ro vessels and ferries are known to be major contributors to erosion near berths. These ship types can be equipped with (Figures 3 and 4):

- Main propellers at the ship's stern: conventional propellers, azimuthal systems (diameter up to $10 \mathrm{~m}$ )

- $\quad$ Thrusters (diameter up to about $3 \mathrm{~m}$ )

- Water jets (outflow opening about $1 \mathrm{~m}$ )

The advantages of azimuthal systems lie in the capacity for rotating the pods, providing $360^{\circ}$ for maneuvering purposes. The total power can reach $25 \mathrm{MW}$.

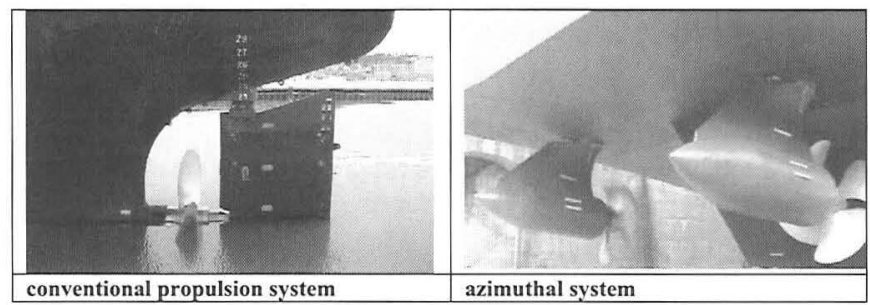

Figure 3. Examples of main propulsion systems

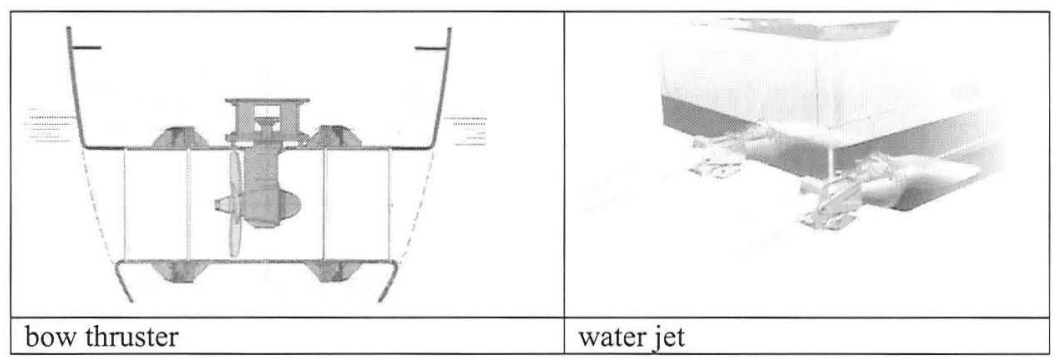

Figure 4. Examples of thrusters and water jets

Thrusters are placed in a smooth tunnel near the bow in single or twin units in different frames, taking in water from one side and expulsing it out the other. They are very useful for turning maneuvers without tug assistance. This subtype is usually called bow thruster when located near the bow, or stern thruster in other positions (aft). Transverse thrusters lose their efficiency at sailing speeds above 2 knots. The power of these systems can reach $4 \mathrm{MW}$.

Fast ferries are often equipped with water jet systems. Sea water passes through a nozzle where an axial pump is located. A considerable jet of water is impelled backwards through the aft pipe system. These jets are usually installed in pairs. Maneuvering is very easy when one jet is pushing forward and the other pulling backward. The installed power of these systems can reach $26 \mathrm{MW}$. 


\section{Design philosophy}

The main distinction in design philosophies is between (Figure 5):

A. Design to protect the bottom in front of the structure in order to avoid scour, or

B. Design to protect the structure in order to avoid negative impacts to the structure resulting from scour

Although in both cases the ultimate goal and result is the protection of the structure, in some cases the designer could decide to accept anticipated scour near the structure but secure the structural integrity in a different way, which in certain cases may be more cost-effective and suitable. It may be more effective and appropriate to design the structure for greater depths taking into account that deep scour holes may develop in front of it, than it would be to put all focus of the design in avoiding any movement or erosion of bed material. Alternatively, a third option of desiogn philosophy could be to focus attention on avoiding scouring forces to happen.

This design philosophy issue is not much different from the usual design question what level of damage to accept in order to optimize a design for long-term functionality and cost-effectiveness over the lifetime of the structure. The answer to that question is highly dependent on the specifics of a situation, and will have to be considered by the designer. Relevant factors that will have to be taken into account are:

- Cost (for both initial construction as well as maintenance)

- Environmental aspects (considerations related to allowing large movements of bed material versus installation of for example a hard bottom protection)

- Options to -and ease of- performing monitoring and any needed maintenance

- Risk to the structure if scour would be more than an acceptable level and/or not detected in time

- Impacts and possibility of performing repair work in case damage to the structure would occur

- Effects on deepening or other berth modifications potentially required in future years

- Any other potential functions of the local bottom (e.g. nearby slopes, buried utilities/outfalls, etc.)

Having made the necessary choices one can start the design. The first step is to compute the outflow velocity taking into account the geometry of the quay structure, berthing procedure, and etcetera.

\section{Berthing and departing procedures}

Sailing speed of a vessel during berthing and departure will be relatively low. One consequence of this low speed is that the vessel's manoeuvrability is significantly reduced and that the vessel cannot rely on the rudder to the same level as during regular sailing speeds. For this reason, assistance from tugs and/or bow thrusters is commonly used during berthing and departure. In some cases and to 
some degree a bow thruster can substitute the workings and/or need of a tug during berthing or departure.

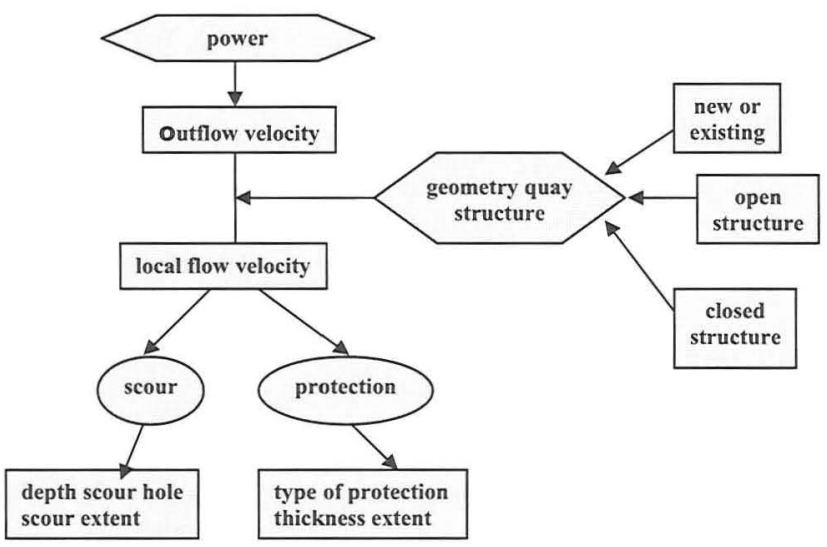

Figure 5. Design process

Main factors in managing a berthing or departure manoeuvre are typically wind and current. Either one can apply great force on a vessel during such manoeuvres and will be a main driver in determining ultimate need for tugs. A certain vessel that may normally depart by use of main propeller and bowthruster may require tug assistance if wind or current are strong. Figure 6 shows berths layouts with unberthing manoeuvres.

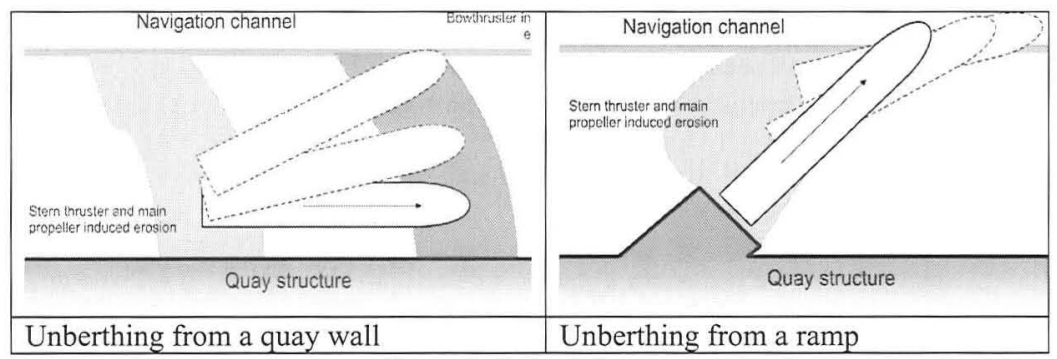

Figure 6. Unberthing manoeuvres

The applied engine power is not constant in time. In the first moments more power will be used. Moreover, the impact of the thrusters depends on the stage of the unberthing manoeuvre. No good data is available on how long captains use their thrusters. Furthermore, it is important to realize that the installed power has increased over time but is not specifically designed for berthing/unberthing but also for carrying out manoeuvres in turning basins in general. In other words: applying 
$100 \%$ of the installed power is a conservative estimate. This is underlined by results of questionnaires of the Harbour Authorities of Antwerp and Rotterdam resulting in the conclusion that use is typically limited to $75 \%$ or less of the installed power of the bow thrusters. The same holds true for the main propellers. In general, the applied power is:

- main propellers: $P_{\text {applied }}=(10-20 \%) \cdot P_{\text {installed }}$ and under strong current and wind conditions the applied power may increase to $40 \%$ of the installed power

- thrusters: always $100 \%$ of installed power, however for very high powered thrusters this might be a too conservative assumption

This requires information on the installed engine power. The ship owner should be able to provide this information. Sometimes, the ship dimensions can help in selecting a reasonable value, for example for container vessels Roubos (2007) presented relations between the ship width $B_{s}$ and the installed power $P_{\text {thruster }}$ as well as for the propeller diameter of thrusters as function of the ship width:

$$
\begin{aligned}
& P_{\text {thruster }}=83 B_{s}-1400 \\
& D_{\text {thruster }}=0.05 B_{s}+0.464
\end{aligned}
$$

Roubos also presented relations for the main propeller system of containers vessels. It should be noted that nowadays the largest container vessels have engines up to $100,000 \mathrm{~kW}$. However, specific equations for all ship types are not available and consequently the designer will have to rely on information from the ship owner.

\section{Flow velocities in thrusters}

In general, jets generated by propulsion systems can be distinghuised from submerged free jets. A free jet is defined as the water flowing out of an orifice into the surrounding water without any disturbance by lateral boundaries or walls that may hinder the spreading of the jet (Albertson et al, 1950). Main differences are: propeller jets have a rotational flow velocity and swirl at the tip of the propeller blades which results in a higher turbulence level and a shorter length of the flow establishment zone compared to free jets.

Based on the free jet approach formulas have been derived to compute the relevant flow velocities for vertical walls (Schmidt, 1998). The maximum flow velocity at the bed in the corner is (Figure 7):

$$
\begin{aligned}
& V_{\text {botsom,thruster }}=\alpha_{L} 1.9 V_{0, \text { thruster }}\left(\frac{x_{t}}{D_{\text {thruster }}}\right)^{-1.0} \text { with } \alpha_{\mathrm{L}}=1 \text { for } \mathrm{h}_{\mathrm{t}} / \mathrm{D}<3 \\
& \text { with the outflow velocity } V_{0, \text { thruster }}=1.15\left(\frac{P_{\text {thruster }}}{\rho_{w} D_{\text {thruster }}^{2}}\right)^{0.33}
\end{aligned}
$$

where $\mathrm{x}_{\mathrm{t}}$ is the distance along the jet axis between outflow opening and quay wall. 
Above a slope the area for flow propagation will be increasingly reduced by the slope and the water level. Research by Schokking (2002) and Römisch (2006) founded that:

$$
\begin{array}{ll}
V_{\text {axis, thrusser }}=1.0 V_{0, \text { thrusser }}\left(\frac{x_{t}}{D_{\text {thrusser }}}\right)^{-0.33} \text { for } 1<\mathrm{x}_{\mathrm{t}} / \mathrm{D}_{\text {thruster }}<6 \\
V_{\text {axis,strusser }}=2.3\left(\frac{x_{t}}{D_{\text {thruster }}}\right)^{-0.825} \quad \text { for } \mathrm{x}_{\mathrm{t}} / \mathrm{D}_{\text {thruster }}>6
\end{array}
$$

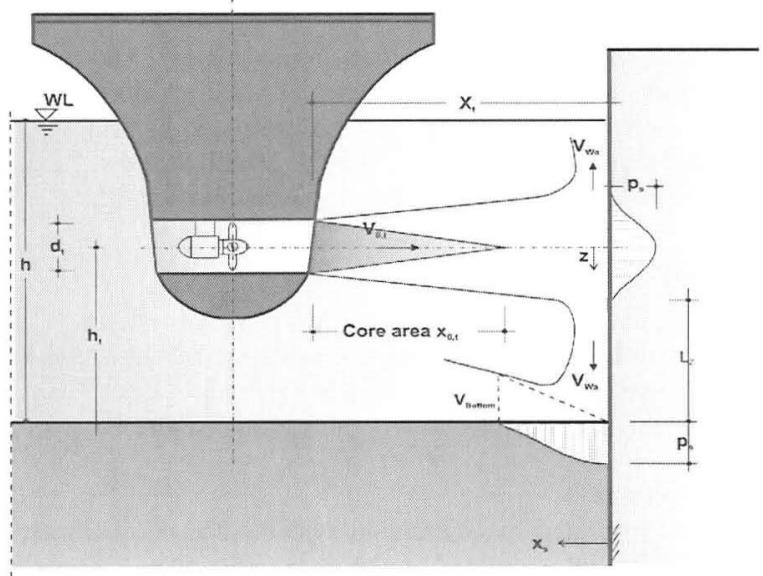

Figure 7. Flow field induced by a bow thruster

\section{Scour prediction}

The flow velocities induced by a thruster may cause scour if those are higher than the threshold value of the bed material. Recently, Römisch (2001) modified equations derived by Schmidt (1998) for scour in front of a closed quay wall (Figure 7) into:

$$
\frac{S}{d_{85}}=C_{m} 4.6\left(\frac{B}{B_{c r}}\right)^{2.25} \text { for } \frac{B}{B_{c r}} \geq 1.4
$$

with $B=\frac{V_{b c d}}{\sqrt{d_{s s} g \Delta}}$ the hydraulic load. Furthermore, the stability criterion $\mathrm{B}_{\mathrm{er}}=1.2$, the relative density $\Delta\left(=\rho_{\mathrm{s}} / \rho-1\right.$ where $\rho_{\mathrm{s}}$ is the specific weight of the bed material and $\rho$ is the specific weight of water) and $C_{m}=0.3$ during berthing maneuvers.

Open quay structures consist of a superstructure built on piles with often, but not necessarily, also a slope underneath. The piles form obstacles for the flow resulting in contraction between the piles and horse shoe vortices at the piles. 


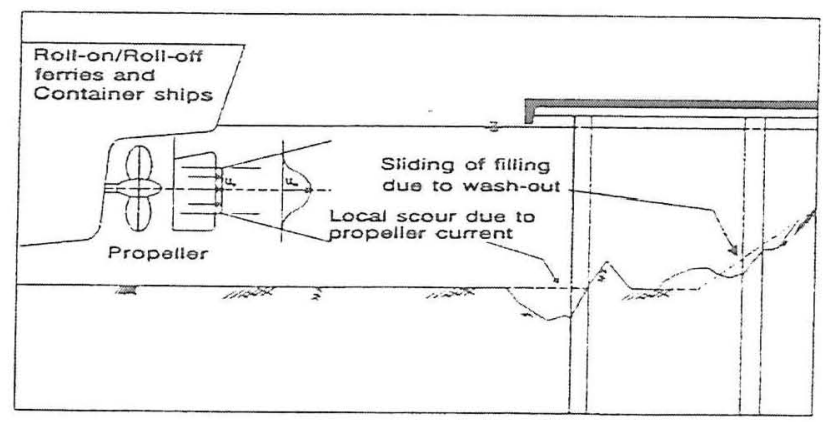

\section{Figure 8. Jet impact on the slope of an open quay structure}

The above means that the following situations will have to be considered regarding the flow field and the subsequent scour below the quay deck (see Figure 8):

- Effect of piles

- Effect on the slope

- Effect of oblique jet

The effect of the slope already has been discussed above, while the effect of the oblique jet can be accounted for by a larger distance. Taking into account the effect of the piles on the flow will be more challenging. Considering thrusters, in most situations the flow direction will be perpendicular to the quay structure. In general, the flow velocity directly adjacent to a pile will be about twice the approach flow velocity (Breusers et al, 1977).

Regarding scour, the pile diameter will be much smaller than the water depth allowing the following formula to be used to estimate the final scour depth (Hoffmans \& Verheij, 1997):

$$
S_{e}=2.0 b
$$

with $b=$ pile diameter.

Mostly, a group of piles supports the superstructure (Figure 9). In those cases, the spacing $\mathrm{s}$ between the piles is important as is the flow direction. If the spacing is larger than about $5 \mathrm{~b}$ the scour holes of the individual piles do not impact each other. If the spacing is less than $5 b$, particular formulas should be used which take into account the different effects (Richardson \& Davis, 2001):

$$
S_{e}=2.0 \mathrm{~Kb} \text { with } K=K_{\text {group }} K_{\text {orientation }} K_{\text {shape }}
$$

The value of the various $\mathrm{K}$-factors vary between 1.0 and 2.0 .

A case study showing how to deal with scour at open quay structures is not available, because to the authors knowledge no particular experiments have been done except by Chin et al (1996). They carried out laboratory tests on scour at quay structures due to propeller jets (Figure 10) and published the results inclusive the following equation for the maximum scour depth $\mathrm{S}_{\mathrm{e}}$ : 


$$
S_{e}=0.21 D_{0} F_{0} \text { with the densimetric Froude number } F_{0}=\frac{V_{0}}{\sqrt{d_{50} g \Delta}}
$$

where $\mathrm{D}_{0}$ is the outflow diameter, $\mathrm{V}_{0}$ the outflow velocity, $\mathrm{d}_{50}$ the median diameter bed material, $\mathrm{g}$ the gravitational constant and $\Delta$ the relative density. Note that the equation derived by Chin et al differs considerably with the earlier presented equations for the scour $\mathrm{S}$ since it does not contain the pile diameter $\mathrm{b}$. It makes clear that research is required.

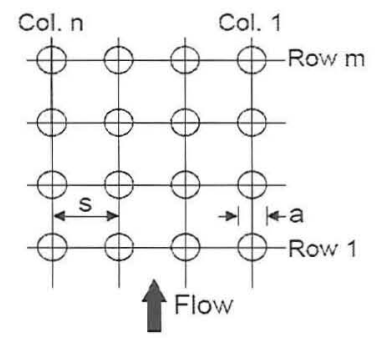

Figure 9. Definition sketch of piles

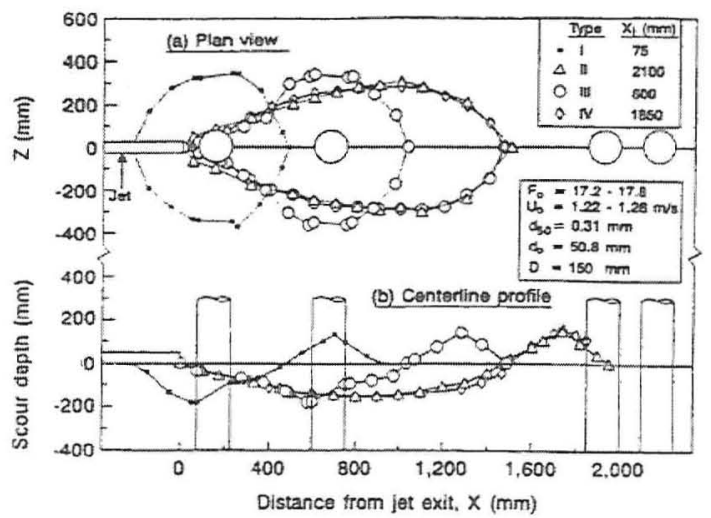

Figure 10. Results of laboratory experiments (Chin et al, 1996)

\section{Conclusions and recommendations}

The new PIANC report "Guidelines for berthing structures related to thrusters" presents procedures to design berthing structures taking into account modern thrusters, complex quay walls and berthing and departure procedures. For solid berth structures, such as gravity walls and sheet pile structures, the procedure is straight forward. For open berth structures, such as a superstructure built on piles above a slope, a straight forward procedure is not available. Based on established well-known design rules for pile structures 
a procedure is proposed. It is recommended to validate the proposed method by carrying out physical tests. Furthermore, it is recommended to collect data on the use of thrusters, particularly the duration and percentage of use of the installed engine power.

\section{References}

Albertson, M.L. et al (1948). Diffusion of submerged jets. ASCE, Trans. Paper No. 2409, pp. 639-664, 1948.

Breusers, H.N.C., G.Nicolet and H.W.Shen (1977). Local scour around cylindrical piers. Journ. of Hydraulic Research, IAHR, 15(3):211-252.

Chin, C.O., Y.M.Chiew, S.Y.Lim and F.H.Lim (1996). Jet scour around vertical pile. Journ. of Waterway, Port, Coastal and Ocean Engineering, Vol.122 No.2, paper No 9787 , pg.59-67

Hoffmans, G.J.C. \& Verheij, H.J. (1997). Scour Manual. Balkema Publishers, Rotterdam

Hoffmans, G.J.C.M. and H.J.Verheij (2008). Three dimensional scour. $4^{\text {rd }}$ Intern. Conf. on Scour and Erosion ICSE-4, paper A-5, pp.128-133, Tokyo, Japan

PIANC (1997). Guidelines for the design of armoured slopes under open piled quay walls. PIANC, report, supplement to Bulletin 22, Brussels.

PIANC (2010). Guidelines for berthing structures related to thrusters. PIANC, Report of working group 48, Brussels, Belgium (in preparation, to be published in 2010).

Richardson, E.V. and S.R.Davis (2001). Evaluating scour at bridges, Hydraulic Engineering Circular no 18 (HEC 18, Fourth Edition). report FHWA NH1-01-001, Federal Highway Administration, Washington DC, USA.

Römisch, K. (2001). Scouring in front of quay walls caused by bow thrusters and New measures for its reduction. $V^{\text {th }}$ Intern. Seminar on Renovation and Improvements to existing Quay Structures, Gdansk, Poland.

Römisch, K. (2006): Erosion potential of bow thrusters on canal banks (in German). Binnenschifffahrt - ZfB - Nr.11.

Roubos, A.A. (2007). Dealing with uncertainties in the design of bottom protection near quay walls. MSc thesis. TU Delft

Sas, M., H.J.Verheij, M.Hermans, G.Horner, E.Schnidt, C.A.Thoresen, J.van Bogaert and J.L.Zatarain (2010). New PIANC guidelines for berthing structures related to thrusters. $32^{\text {nd }}$ Intern. Congress, PIANC, Liverpool, UK.

Schmidt, E. (1998). Diffusion and erosion of a bow thruster jet in front of a quay wall (in German). MSc thesis, TU Braunschweig, Mitteilungen des Leichtweiss-Institutes, Heft 143, Braunschweig, Germany. 